\title{
Classification of aluminium alloy cross-sections
}

DOI:

10.1016/j.engstruct.2017.03.007

\section{Document Version}

Accepted author manuscript

Link to publication record in Manchester Research Explorer

\section{Citation for published version (APA):}

Su, M. N., Young, B., \& Gardner, L. (2017). Classification of aluminium alloy cross-sections. Engineering Structures, 141, 29-40. https://doi.org/10.1016/j.engstruct.2017.03.007

\section{Published in:}

Engineering Structures

\section{Citing this paper}

Please note that where the full-text provided on Manchester Research Explorer is the Author Accepted Manuscript or Proof version this may differ from the final Published version. If citing, it is advised that you check and use the publisher's definitive version.

\section{General rights}

Copyright and moral rights for the publications made accessible in the Research Explorer are retained by the authors and/or other copyright owners and it is a condition of accessing publications that users recognise and abide by the legal requirements associated with these rights.

\section{Takedown policy}

If you believe that this document breaches copyright please refer to the University of Manchester's Takedown Procedures [http://man.ac.uk/04Y6Bo] or contact uml.scholarlycommunications@manchester.ac.uk providing relevant details, so we can investigate your claim.

\section{OPEN ACCESS}


Su, M., Young, B. and Gardner, L. (2017) "Classification of Aluminium Alloy Cross-sections", Engineering Structures, 141: 29-40.

\title{
Classification of Aluminium Alloy Cross-sections
}

\author{
Mei-Ni Su${ }^{1}$, Ben Young ${ }^{2}$ and Leroy Gardner ${ }^{3}$
}

\begin{abstract}
Cross-section classification is one of the key concepts in the design of metallic structures. Current design specifications for aluminium alloys, such as Eurocode 9 (EC9), provide clear definitions and discrete design capacities for four different classes of cross-section. On the basis of substantial, recently generated experimental and numerical data on aluminium alloy cross-sections collected from the literature, the purpose of the present study is to re-evaluate the slenderness limits that define these classes. A total of approximately 900 relevant data points have been gathered, covering stub columns, simply supported beams and continuous beams; the cross-section types include square and rectangular hollow sections (SHS/RHS) with and without internal stiffeners, I-sections, channels and angles. The members were extruded from a variety of aluminium alloy tempers with a wide range of yield and ultimate strengths. Following analysis of the available data, the slenderness limits in EC9 have been re-assessed, and new slenderness limits in the EC9 framework are proposed. In addition, the full cross-section slenderness allowing for element interaction, which is utilised in the direct strength method (DSM) and the continuous strength method (CSM) has been considered as the slenderness parameter in a new classification framework. Corresponding slenderness limits, together with a compatible effective thickness formula for Class 4 sections, are proposed. The suitability of the proposed limits has been demonstrated for the conventional design methods in EC9, as well as the alternative methods in Annexes F and H of EC9.
\end{abstract}


KEY WORDS: Aluminium alloys; Continuous beams; Continuous strength method (CSM); Cross-section classification; Effective thickness formula; Reliability analysis; Simply supported beams; Slenderness limits; Stub columns

\footnotetext{
${ }^{1}$ Assistant professor, Dept. of Civil Engineering, Shenzhen University, Nanshan, Shenzhen, China

${ }^{2}$ Professor, Dept. of Civil Engineering, The University of Hong Kong, Pokfulam Road, Hong Kong. E-mail: young@hku.hk

${ }^{3}$ Professor, Dept. of Civil and Environmental Engineering, Imperial College London, London SW7 2AZ, UK. E-mail: leroy.gardner@imperial.ac.uk
}

\section{Introduction}

Section classification addresses the susceptibility of a cross-section to local buckling and defines its appropriate design resistance [1]. This concept, which is adopted in Eurocode 9 (EC9) [2], treats cross-sections on an element by element basis, ignoring the benefit of element interaction, and utilises an elastic-perfectly plastic material model, excluding the beneficial influence of strain hardening. Ignoring these two effects is generally conservative, as illustrated later, when the classification criteria in EC9 are re-assessed against approximately 900 experimental and numerical results.

As an alternative to the EC9 classification framework, utilisation of the full crosssection slenderness as the slenderness parameter, as adopted in the continuous strength method (CSM) [3] and the direct strength method (DSM) [4], is considered. Note that this classification framework is therefore called 'classification based on full cross-section slenderness' to distinguish it from the traditional EC9 classification framework. Departing from the existing EC9 slenderness definition, the full cross-section slenderness parameter, 
$\bar{\lambda}_{p}$, as defined in Equation (1), where $f_{y}$ is the material yield stress (or $0.2 \%$ proof stress) and $\sigma_{c r}$ is the elastic buckling stress of the full cross-section under the applied stress distribution, considering both the interaction between the constituent elements of the cross-section and the loading to which the cross-section is subjected.

$$
\bar{\lambda}_{p}=\sqrt{f_{y} / \sigma_{c r}}
$$

The two section classification frameworks provide discrete design capacities for four different classes of cross-section [5]. On the basis of a large collected pool of experimental and numerical results described in Section 2 of this paper, revised slenderness limits for the existing EC9 classification framework (Section 3) and the full cross-section slenderness framework (Section 4) are proposed. Slender (Class 4) cross-sections are considered in Section 5, while comparisons and reliability analyses are presented in Section 6.

\section{Review of existing experimental and numerical data}

Previous test data on aluminium alloy stub columns, simply supported beams and continuous beams, together with numerical results from parametric studies, have been collected and analysed herein. The assembled results are summarised below.

\subsection{Stub columns}

Stub column test results on different aluminium alloy tempers and a wide range of cross-section types of various proportions have been collected. The stub column data pool includes a total of 346 results, with both closed and open sections: 110 square and rectangular hollow sections (SHS/RHS) [6-14], 203 plain channel sections [12, 15] and 33 angle sections [16]. The average measured cross-sectional dimensions and material properties can be found 
in the cited papers. The specimens cover all four classes of cross-sections, as defined by EC9 $[2]$.

\subsection{Simply supported beams}

For cross-sections in bending, 53 experimental data points obtained from three-point bending tests on SHS/RHS and I sections [18-20], as well as 38 data points from four-point bending tests on SHS/RHS [17, 18, 19, 21, 22] have been assembled. In addition, a total of 192 numerical results from validated finite element models of aluminium alloy beams (half in three-point bending and half in four-point bending) have been collected [18 and 19]. A wide spectrum of $b / h$ (width-to-height) ratios (0.3-3.6) and $b / t$ (width-to-thickness) ratios (4.355.1) are covered by the numerical results.

\subsection{Continuous beams}

For continuous beams, data from an experimental program featuring 46 SHS/RHS test specimens with and without internal cross stiffeners [19, 23], have been collected. The beams were tested in three symmetrical five-point bending configurations. Both normal strength (i.e. 6063-T5) and high strength (i.e. 6061-T6) aluminium alloys were considered. In addition to the experiments, a numerical parametric study was also conducted, and the 210 generated results $[19,24]$ are utilised in the present study.

\section{EC9 classification framework}

EC9 [2] defines four classes of cross-sections, while the American [25] and Australian/New Zealand [26] specifications classify cross-sections into three categories according to their failure modes: yielding (equivalent to Classes 1 and 2 in EC9), inelastic 
buckling (equivalent to Class 3 in EC9) and elastic buckling (equivalent to Class 4 in EC9). There is also some variation between the slenderness limits adopted in the different design standards - this is attributed to the pool of available structural performance data utilised in their development and to the different regional practice in terms of structural reliability [27].

The classification of cross-sections in EC9 [2] depends on their most slender constituent element. The adopted slenderness measure is $\beta / \varepsilon$, which takes account of the flat width-to-thickness ratio of the element $b / t$ and the yield stress $f_{y}$, as given by Equation (2). A reduction factor is used to allow for the applied stress distribution. For example, for elements in pure bending, the element width is multiplied by a reduction factor of 0.4 , as given by Equation (3).

$$
\begin{aligned}
& \frac{\beta}{\varepsilon}=\frac{b / t}{\sqrt{250 / f_{y}}} \\
& \frac{\beta}{\varepsilon}=\frac{0.4 b / t}{\sqrt{250 / f_{y}}}
\end{aligned}
$$

Note that the unit of $f_{y}$ must be in MPa.

Slenderness limits are given in Table 5.2 of EC9, and repeated in Table 1 of the present paper. These limits depend on the way in which the elements are supported (either one edge supported as outstand elements or two edges supported as internal elements), the stress distribution (uniform compression or varying stresses), and the heat treatment. Since the influence of stress distribution is considered when calculating the slenderness $\beta / \varepsilon$, the same class limits are applied to both uniform compression and flexural elements. Table 1 also presents slenderness limits from EN 1993-1-1 [28] for carbon steel and EN 1993-1-4 [29] for stainless steel. Owing to the differences in the Young's Modulus, the Poisson's ratio and the base strength used to normalize the yield stress between the different codes, the aforementioned limits have been converted to a common basis that is compatible with the EC9 slenderness definition. 
Table 1: Existing and proposed slenderness limits for the EC9 classification framework

\begin{tabular}{|c|c|c|c|c|c|c|c|c|}
\hline \multirow{2}{*}{$\begin{array}{c}\text { Slenderness } \\
\text { parameter }\end{array}$} & \multirow{2}{*}{ Reference } & \multirow{2}{*}{ Material } & \multicolumn{2}{|c|}{ Class 1} & \multicolumn{2}{|c|}{ Class 2} & \multicolumn{2}{|c|}{ Class 3} \\
\hline & & & Internal & Outstand & Internal & Outstand & Internal & Outstand \\
\hline \multirow{5}{*}{$\beta / \varepsilon$} & \multirow{2}{*}{ EC9 } & $\begin{array}{c}\text { Aluminium- } \\
\text { Class A }\end{array}$ & 11.0 & 3.0 & 16.0 & 4.5 & 22.0 & 6.0 \\
\hline & & $\begin{array}{c}\text { Aluminium- } \\
\text { Class B }\end{array}$ & 13.0 & 3.5 & 16.5 & 4.5 & 18.0 & 5.0 \\
\hline & EN 1993-1-1 & Carbon Steel & 19.1 & 5.2 & 21.9 & 5.8 & 24.2 & 8.1 \\
\hline & EN 1993-1-4 & $\begin{array}{c}\text { Stainless } \\
\text { Steel }\end{array}$ & 14.8 & 5.8 & 15.4 & 6.0 & 17.7 & 6.9 \\
\hline & $\begin{array}{c}\text { Proposed } \\
\text { herein }\end{array}$ & $\begin{array}{l}\text { Aluminium- } \\
\text { Class A \& B }\end{array}$ & 15.0 & - & 16.0 & - & 22.0 & 6.0 \\
\hline
\end{tabular}

\subsection{Cross-sections in compression}

For cross-sections under pure compression, the key concern is whether the section is 'fully effective'. Those cross-sections that can attain the yield load are considered to be 'fully effective', and are defined in EC9 [2] as being either of Class 1, Class 2 or Class 3, while Class 4 sections fail by local buckling below the yield load. Hence, the design capacities for Classes 1, 2 and 3 sections are the yield load $A f_{y}$, while for Class 4 sections, the gross area $A$ is replaced by the effective area $A_{\text {eff }}$, determined on the basis of a reduced thickness $t_{\text {eff }}$ to allow for local buckling. This is discussed further in Section 5.1 of the paper.

\subsubsection{Class 3 slenderness limit}

The slenderness limits in EC9 [2] are presented individually for different aluminium alloys, categorised as either Class A or B materials in Table 3.2 of the code. In order to assess the accuracy of the current class limits, the normalized ultimate loads $N_{u} / A f_{y}$ from the collected experiments are plotted against the slenderness $\beta / \varepsilon$ of the most slender element in the cross-section in Fig. 1. The results generally follow the anticipated trend whereby sections with greater slenderness have lower normalised capacity. Fig. 1(a) shows the data for internal elements of Class A material, while Fig. 1(b) presents the data for internal elements 
of Class B material; the corresponding Class 3 limits of $\beta / \varepsilon=22.0$ and $\beta / \varepsilon=18.0$ are indicated in both figures. Figs 1(a) and 1(b) show that the results from Class A and Class B aluminium alloy stub columns are closely aligned and, although the number of test results for Class B material is rather limited at this stage, it is recommended that the limits for the two materials can be harmonised at $\beta / \varepsilon=22.0$ (also supported by the results of the bending tests presented in Section 3.2). The compression test data for outstand elements of Class A material are plotted in Fig. 1(c), together with the corresponding Class 3 limit $\beta / \varepsilon=6.0$ for Class A alloys and $\beta / \varepsilon=5.0$ for Class B alloys. No compression test results have been obtained on cross-sections with outstand elements of Class B materials from the literature. It is proposed to retain the Class 3 limit at $\beta / \varepsilon=6.0$ for outstand elements of Class A material, as indicated in Fig. 1(c).

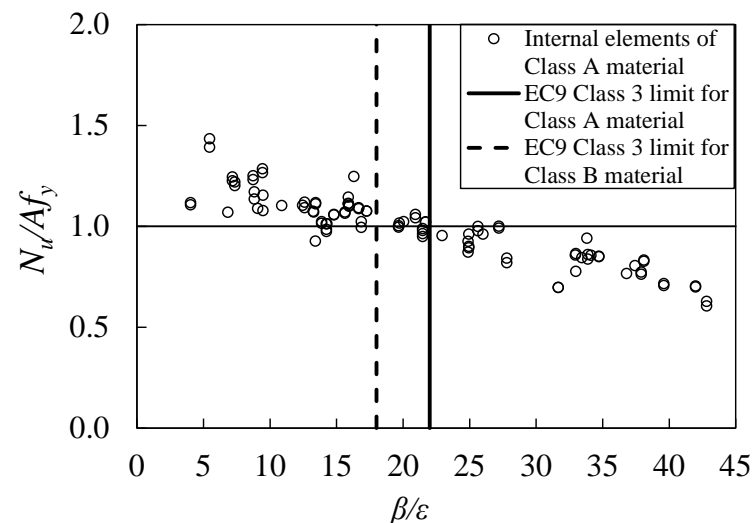

(a)

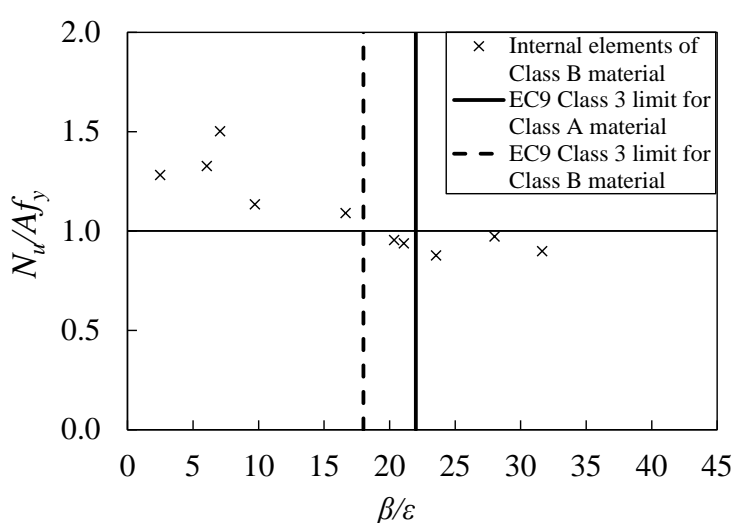

(b)

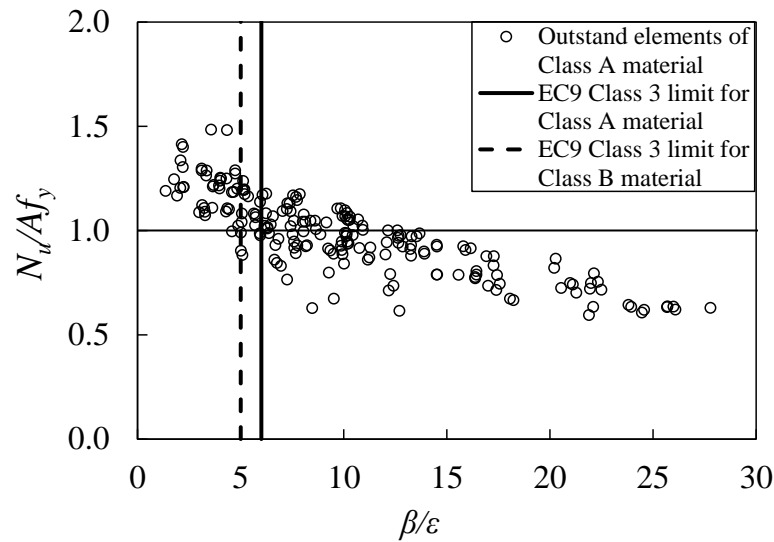

(c)

Fig. 1. Comparisons between stub column results and EC9 Class 3 boundaries for (a) internal elements of Class A material, (b) internal elements of Class B material and (c) outstand elements of Class A material 


\subsection{Cross-sections in bending}

Cross-section classification criteria for members in bending relate to rotation capacity and attainable resistance. As introduced earlier, slenderness limits are given in EC9 [2] for four cases (internal and outstand elements of Class A and B materials) for non-welded elements. Relevant test and numerical results have been collected to verify each of these limits, though data for outstand elements of Class A material are scarce and no data were found for outstand elements of Class B material. Thus, discussions made herein are focused on internal elements. Utilising the collected results, the ratio of the experimental/numerical moment capacity to the elastic moment capacity $\left(M_{u} / W_{e l} f_{y}\right)$ is plotted against slenderness $\beta / \varepsilon$ in Fig. 2, the ratio of experimental/numerical moment capacity to the plastic moment capacity $\left(M_{u} / W_{p l} f_{y}\right)$ is plotted in Fig. 3 and the rotation capacity $R$ is plotted in Fig. 4 . Based on these plots, the slenderness limits for Class 3, 2 and 1 cross-sections are assessed in the following sub-sections.

\subsubsection{Class 3 slenderness limit}

Class 3 cross-sections in bending are defined as those capable of reaching the elastic moment capacity (i.e. the moment corresponding to first yield), but fail by local buckling before becoming fully plastic. Thus, the flexural capacities of Class 3 cross-sections are the product of the yield stress $f_{y}$ and the elastic section modulus $W_{e l}$. Class 4 sections, on the other hand, fail by local buckling prior to first yield, and their resistances may be determined by calculating the elastic section modulus of an effective cross-section obtained based on an effective thickness concept.

Analysis of the bending data reveals that the results for the Class A and Class B material are again closely aligned and that a harmonised Class 3 slenderness limit for internal elements of $\beta / \varepsilon=22.0$ appears appropriate - see Figs 2(a) and 2(b). Fig. 2(c) shows that the 
current Class 3 limit for outstand elements of Class A material is on the safe side, though the available data are rather limited and further investigation is required.

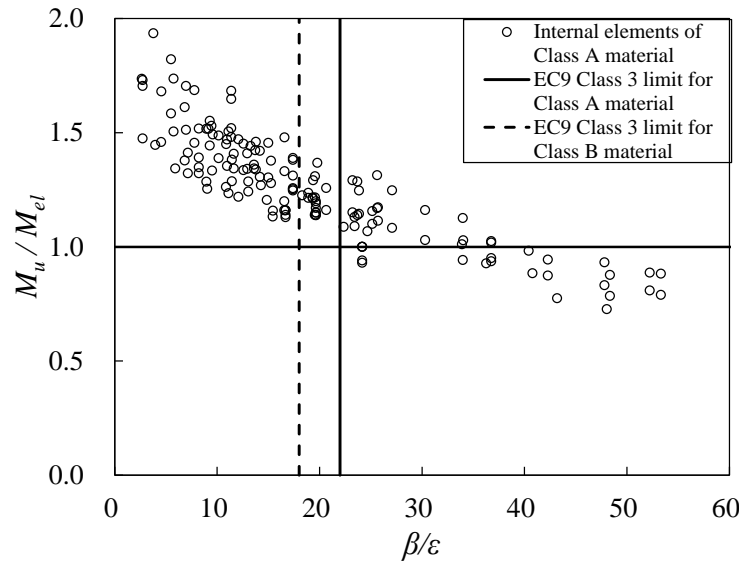

(a)

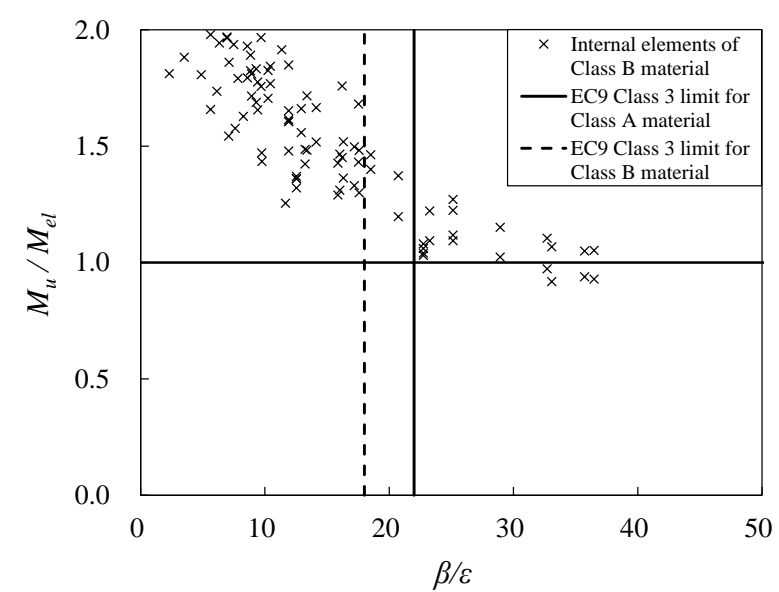

(b)

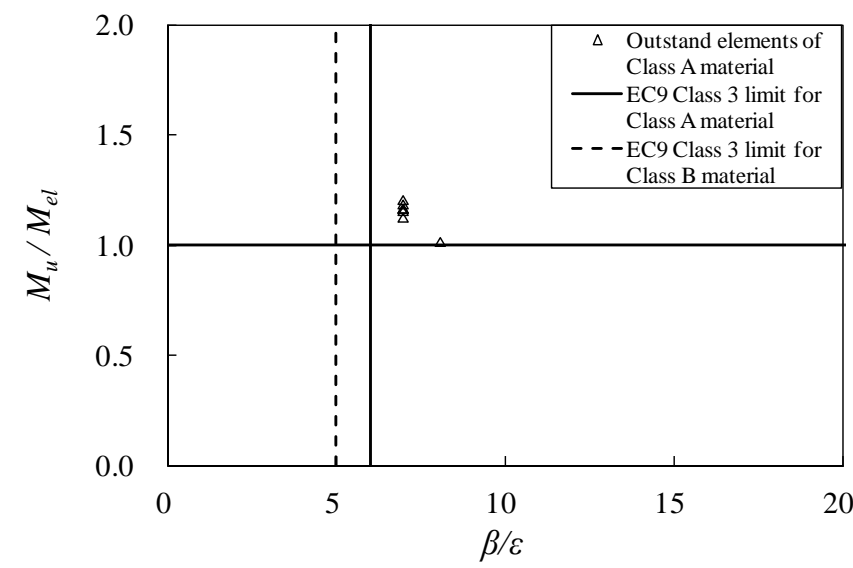

(c)

Fig. 2. Assessment of EC9 Class 3 slenderness limits for (a) internal elements of Class A material, (b) internal elements of Class B material and (c) outstand elements of Class A material

\subsubsection{Class 2 slenderness limit}

Class 2 cross-sections are defined as those that are able to develop their full plastic moment capacity but do not have sufficient rotation capacity to allow moment redistribution (i.e. plastic design). As defined in EC9 [2], the bending resistance of Class 2 cross-sections is hence the product of the yield stress $f_{y}$ and the plastic section modulus $W_{p l}$. With this in mind, the experimental/numerical results for ultimate moment $M_{u}$ normalised by the plastic moment $W_{p l} f_{y}$ are plotted against the slenderness $\beta / \varepsilon$ in Fig. 3, together with the current Class 2 slenderness limits of EC9 [2]. 
The available experimental and numerical results in Fig. 3 display the anticipated trend of decreasing normalised moment capacity $M_{u} / W_{p l} f_{y}$ with increasing slenderness $\beta / \varepsilon$. The distinction between a Class 2 and Class 3 cross-section is made on the basis of whether or not the bending capacity reaches the plastic moment. In Figs 3(a) and 3(b), it is found that the current Class 2 limits in EC9 [2] can appropriately separate these cross-sections according to the aforementioned requirement. Furthermore, the Class 2 slenderness limits for internal elements of Class A $(\beta / \varepsilon=16.0)$ and Class B materials $(\beta / \varepsilon=16.5)$ are extremely close, and it would seem reasonable to harmonise these limits at the value of 16 . The limited test results on outstand elements are shown in Fig. 3(c), which demonstrate the suitability of the current slenderness limit, with some scope for relaxation were further data to become available.

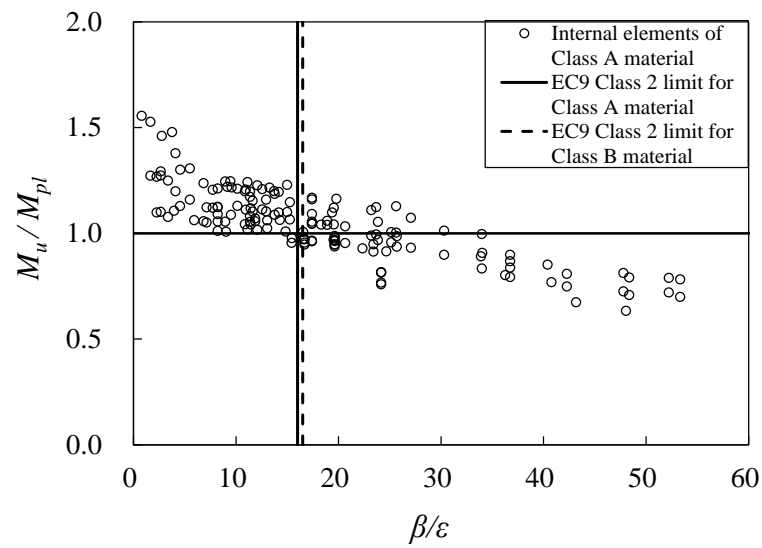

(a)

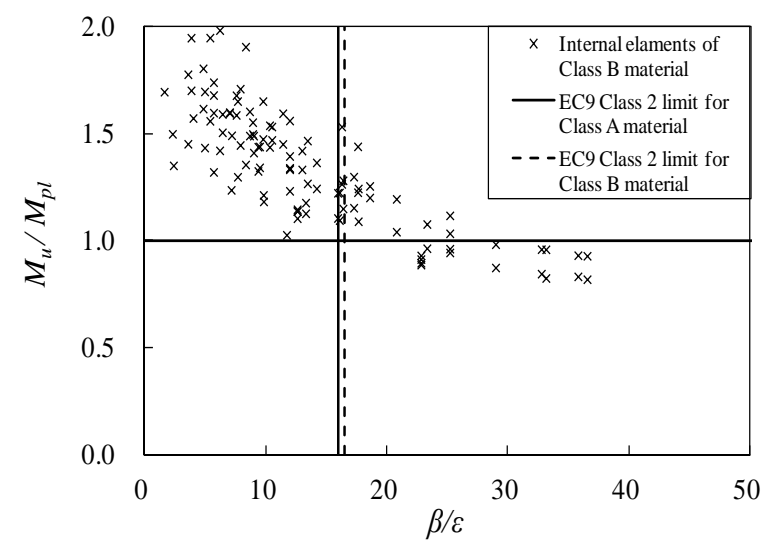

(b)

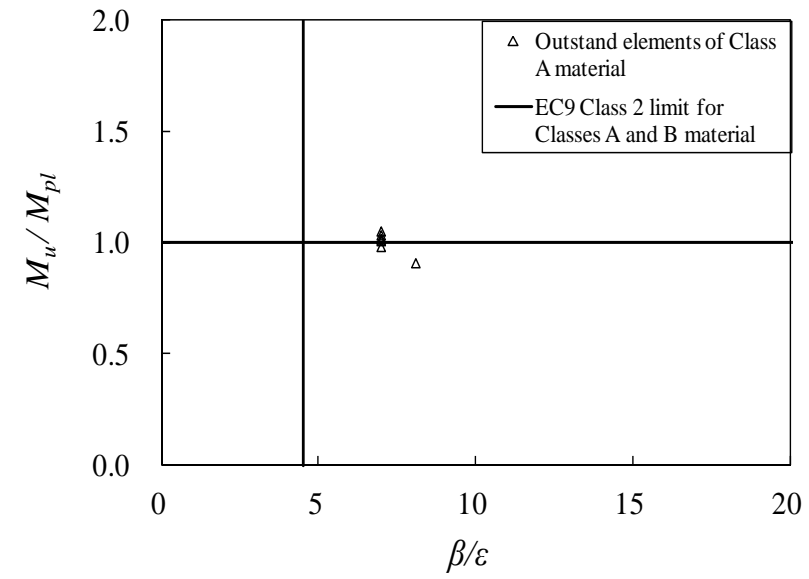

(c)

Fig. 3. Assessment of EC9 Class 2 slenderness limits for (a) internal elements of Class A material, (b) internal elements of Class B material and (c) outstand elements of Class A material 


\subsubsection{Class 1 slenderness limit}

Class 1 cross-sections are defined as those that are capable of reaching and maintaining their full plastic moment resistance with sufficient rotation capacity to ensure moment redistribution and the formation of a plastic collapse mechanism in indeterminate structures. The distinction between Class 1 and Class 2 sections is therefore made on the basis of the available rotation capacity $R$, as defined by Equations (4) and (5). A required rotation capacity $R=3$ is generally deemed sufficient for the plastic design of steel structures [30], and this value is also adopted in the present study for aluminium alloys.

$$
\begin{aligned}
& R=\frac{\theta_{r o t}}{\theta_{p l}}-1 \\
& R=\frac{\kappa_{r o t}}{\kappa_{p l}}-1
\end{aligned}
$$

Equations (4) and (5) are used to determine the rotation capacity from three-point and four-point bending tests respectively, where $\theta_{p l}$ and $\kappa_{p l}$ are the elastic rotation and curvature corresponding to the plastic moment capacity $M_{p l}$ and, $\theta_{r o t}$ and $\kappa_{r o t}$ are the rotation and curvature at the point where the moment resistance drops back below $M_{p l}$.

The collected rotation capacity results are plotted against slenderness $\beta / \varepsilon$ in Fig. 4. Similar to equivalent data from carbon steel [31] and stainless steel [32 and 33], significant scatter exists in the rotation capacities of aluminium alloy beams. This is attributed largely to the effects of moment gradient, material properties, the interaction of constituent plates, as well as premature tensile fracture in the case of some of the less ductile aluminium tempers. There is also generally inherent scatter associated with characteristics that are based on horizontal measures (e.g. rotation capacity) on relatively flat regions of graphs (e.g. moment - 
rotation curves). In common with other design treatments, only the influence of element slenderness on rotation capacity is considered herein. Despite the scattered nature of the data, the anticipated trend is clear, and the Class 1 slenderness limits for Class A and B materials, currently lying at $\beta / \varepsilon=11.0$ and 13.0 respectively, may be seen to be rather strict, particularly when compared to the more relaxed limits applied to carbon steel [28] and stainless steel [29] - see Table 1. A Class 1 slenderness limit of $\beta / \varepsilon=15.0$, in line with stainless steel, for both Class A (Fig 4(a)) and B (Fig 4(b)) material is proposed herein based on the collected aluminium alloy data. Unfortunately, no rotation capacity data for outstand elements were found in the literature and thus the corresponding limits cannot be assessed.

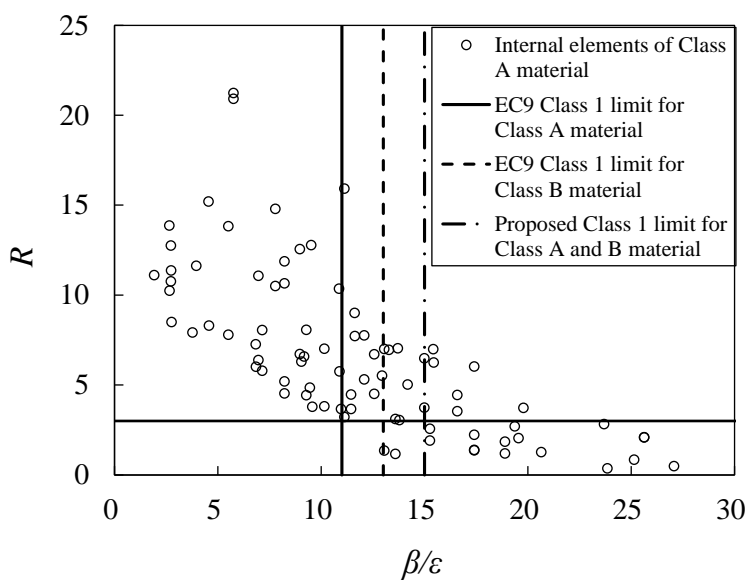

(a)

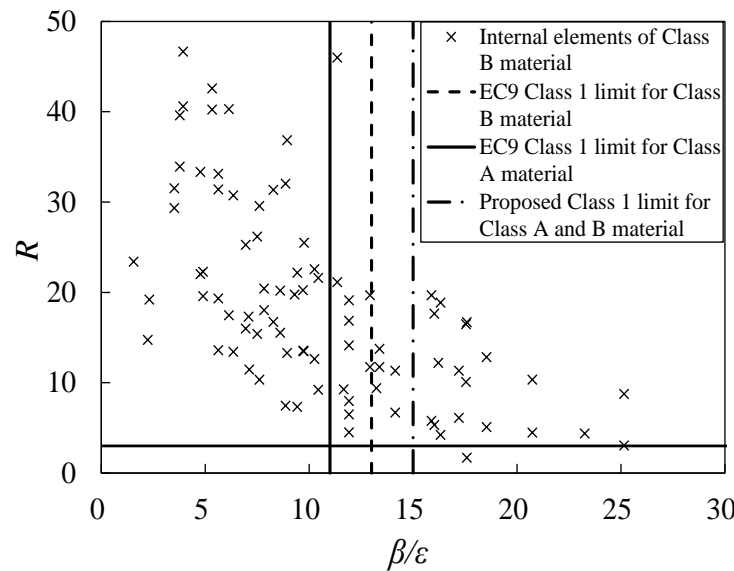

(b)

Fig. 4. Assessment of EC9 Class 1 slenderness limit for (a) internal elements of Class A material and (b) internal elements of Class B material

A summary of the proposed slenderness limits in the EC9 classification framework is given in Table 1. 


\section{Classification based on full cross-section slenderness}

A drawback to the existing EC9 classification framework [2] is that the slenderness parameter $\beta / \varepsilon$ does not account for the interaction between the constituent elements that make up the cross-section, and classification is based on the most slender element. This does not present a problem for cross-sections comprising elements of equal slenderness, e.g. SHS in pure compression, which were used to establish the slenderness limits in EC9, as explained by Faella [34]. However, when this is not the case, the more slender elements receive additional restraint from the less slender elements, improving their boundary conditions and enhancing their buckling stress [34-36]. In this section of the paper, a new local buckling classification framework for aluminium alloys, based on the slenderness of the full crosssection (see Table 2), is described.

\subsection{Slenderness parameter}

Local slenderness is the key parameter for cross-section classification. Following the continuous strength method (CSM) [3] and the direct strength method (DSM) [4], the proposed classification system uses the full cross-section local slenderness $\bar{\lambda}_{p}$ (see Equation (1)) to replace the EC9 slenderness parameter $\beta / \varepsilon$. The elastic local buckling stress $\sigma_{c r}$ used in Equation (1) is for the full cross-section, allowing for interaction between elements, i.e. unlike considering local buckling on an element by element basis, by considering a single elastic buckling stress of the full cross-section allows more slender elements to benefit from restraint from less slender adjoining elements. This elastic buckling stress can be determined by means of analytical approximations [36], numerical tools, such as finite element or finite strip analysis (e. g. CUFSM [37]), or any other rational means. In the present study, the software CUFSM [37] was used. 
Table 2: Existing and proposed slenderness limits in the classification framework based on full crosssection slenderness

\begin{tabular}{|c|c|c|c|c|c|c|c|c|}
\hline \multirow{2}{*}{$\begin{array}{l}\text { Slenderness } \\
\text { parameter }\end{array}$} & \multirow{2}{*}{ Reference } & \multirow{2}{*}{ Material } & \multicolumn{2}{|c|}{ Class 1} & \multicolumn{2}{|c|}{ Class 2} & \multicolumn{2}{|c|}{ Class 3} \\
\hline & & & Internal & Outstand & Internal & Outstand & Internal & Outstand \\
\hline \multirow{3}{*}{$\bar{\lambda}_{p}$} & \multirow{2}{*}{ EC9 } & $\begin{array}{c}\text { Aluminium- } \\
\text { Class A }\end{array}$ & 0.34 & 0.28 & 0.50 & 0.43 & 0.68 & 0.57 \\
\hline & & $\begin{array}{c}\text { Aluminium- } \\
\text { Class B } \\
\end{array}$ & 0.40 & 0.33 & 0.51 & 0.43 & 0.56 & 0.47 \\
\hline & $\begin{array}{l}\text { Proposed } \\
\text { herein }\end{array}$ & $\begin{array}{l}\text { Aluminium- } \\
\text { Class A \& B }\end{array}$ & \multicolumn{2}{|c|}{0.45} & \multicolumn{2}{|c|}{0.50} & \multicolumn{2}{|c|}{0.68} \\
\hline
\end{tabular}

\subsection{Class 3 slenderness limit}

To determine the Class 3 slenderness limit for stub columns, the ability of the crosssection to attain the yield load $A f_{y}$ is assessed. Classes 1, 2 and 3 sections should be capable of reaching this yield load prior to failure by local buckling, and meanwhile these sections may also benefit from strain hardening under increasing plastic strains. Conversely, stub columns with Class 4 sections fail by local buckling before reaching the yield load. The collected stub column test results are plotted in Fig. 5, which also includes the slenderness limit from the CSM [6], $\bar{\lambda}_{p}=0.68$, that denotes the boundary between non-slender and slender sections. In the CSM, at $\bar{\lambda}_{p}=0.68$, the cross-section limiting stress $f_{c s m}$ is equal to the yield stress $f_{y}$, while $\bar{\lambda}_{p} \leq 0.68$ leads to $f_{c s m}$ greater than $f_{y}$, and vice versa [38]. The slenderness limit between non-slender and slender sections in a proposed extension of the DSM [4] to aluminium alloys by Zhu and Young [17] was 0.713. 


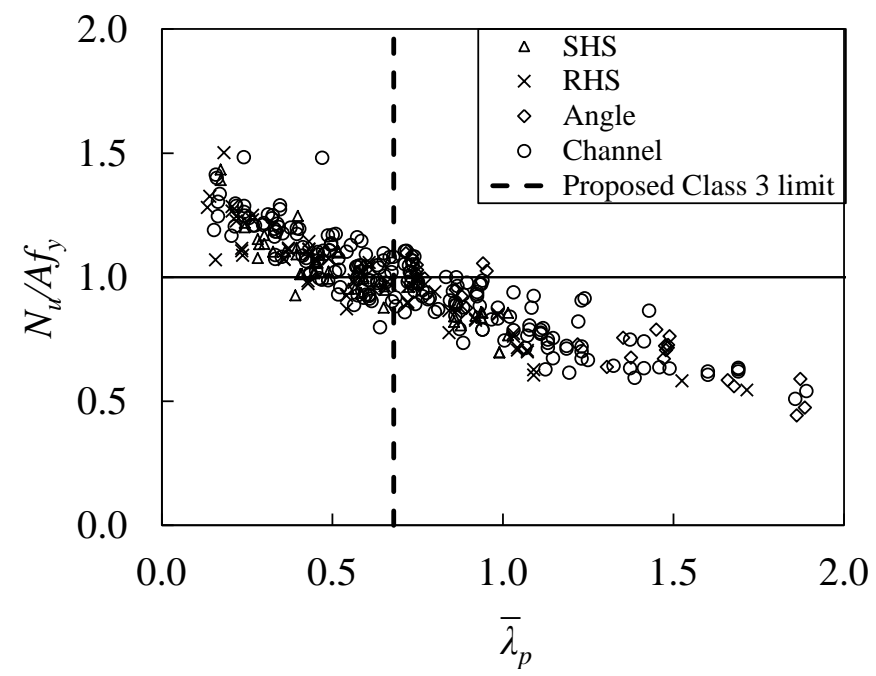

Fig. 5. Stub column test results and assessment of full cross-section Class 3 slenderness limit

The collected bending test and FE moment capacities $M_{\mathrm{u}}$ are normalised by the elastic moment capacity $M_{\mathrm{el}}$ and plotted against the full cross-section slenderness in Fig. 6 to assess the Class 3 slenderness limit. As for stub columns, the CSM slenderness limit of $\bar{\lambda}_{p}=0.68$ appears approximate to differentiate between slender and non-slender cross-sections and is recommended herein.

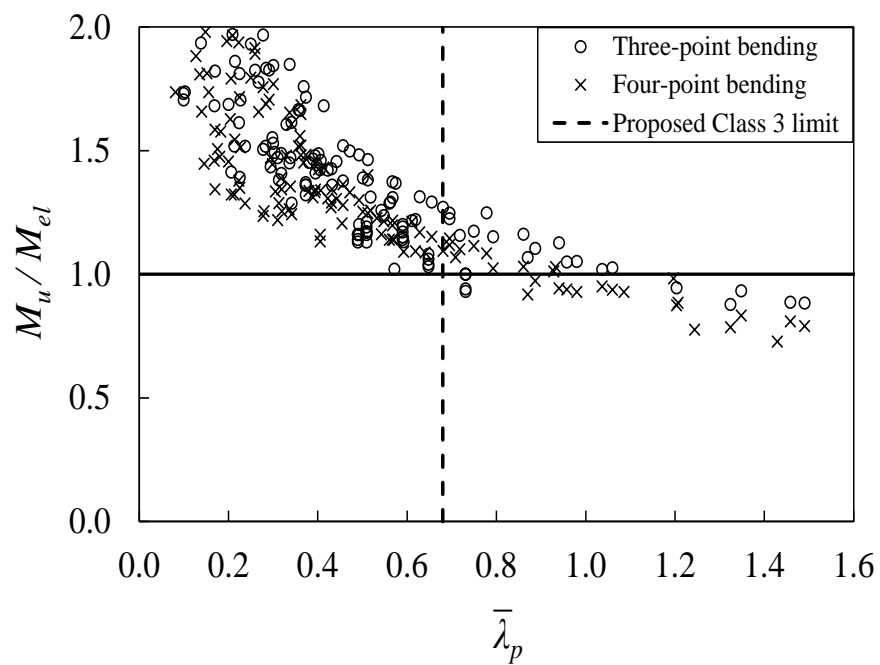

Fig. 6. Bending test and FE results and assessment of full cross-section Class 3 slenderness limit 


\subsection{Class 2 slenderness limit}

Class 2 cross-sections are able to reach their plastic moment resistance but have insufficient rotation capacity to allow plastic design. The moment capacities from the collected tests and FE simulations have been normalised by the plastic moment capacity $M_{p l}$ and plotted against the full cross-section slenderness in Fig. 7. The Class 2 slenderness limit equivalent to that of $\beta / \varepsilon=16$ in the EC9 framework is $\bar{\lambda}_{p}=0.50$, which may be seen in Fig. 7 to provide a good representation of the point at which the collected data pass through $M_{u} / M_{p l}$ $=1.0$. The value of $\bar{\lambda}_{p}=0.50$ for the full cross-section Class 2 slenderness limit is therefore proposed.

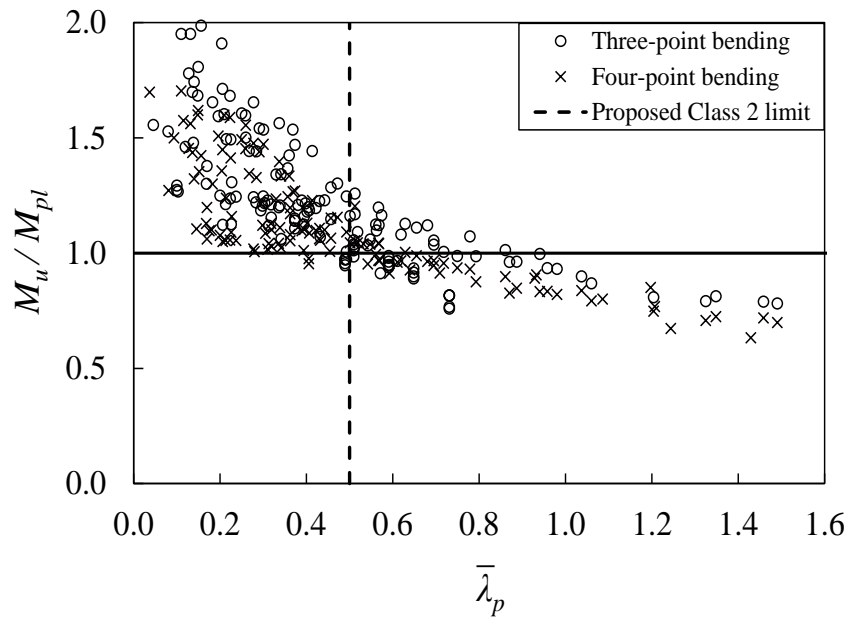

Fig. 7. Bending test and FE results and assessment of full cross-section Class 2 slenderness limit

\subsection{Class 1 slenderness limit}

As discussed in Section 3.2.3 of this paper, distinction between Class 1 and Class 2 cross-sections is made on the basis of rotation capacity, with $R=3$ being the most commonly adopted delineating criterion. The collected test and FE data are plotted in Fig. 8 on a graph of rotation capacity versus full cross-section slenderness. Although the data are rather scattered, a Class 1 full cross-section slenderness limit of $\bar{\lambda}_{p}=0.45$ may be seen to offer a 
good representation of where the assembled results pass through $R=3$, and this value is therefore proposed herein.

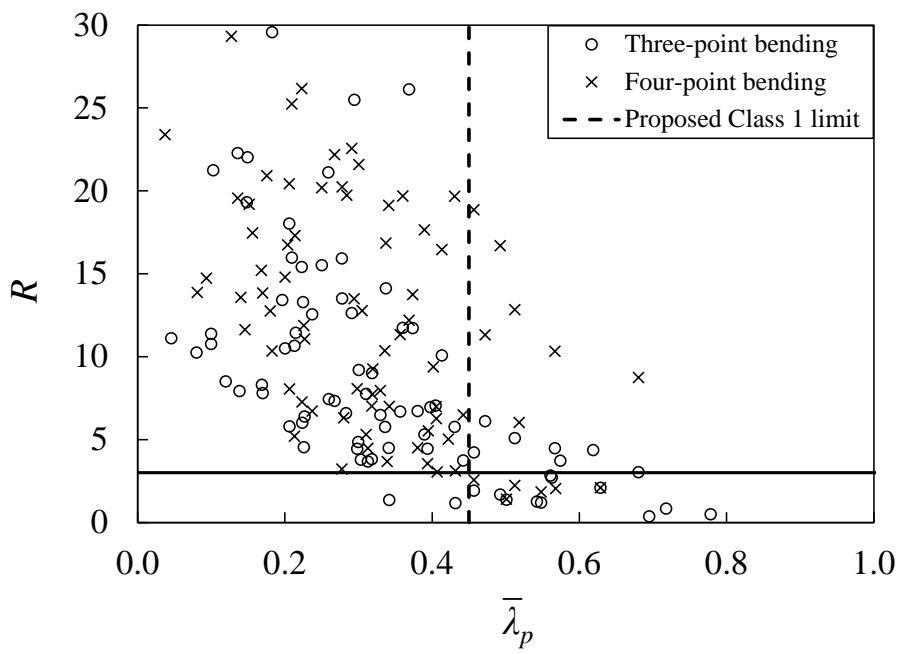

Fig. 8. Rotation capacities from bending tests and FE models and assessment of full cross-section Class 1 slenderness limit

\section{$5 \quad$ Slender cross-sections - effective thickness formulae}

Compression or flexural members with Class 4 sections fail by local buckling prior to first yield. A reduced design capacity must therefore be defined. For stub columns, the reduction factor $\rho_{c}$ may be expressed approximately (disregarding corners) through Equation (6).

$$
\frac{N_{u}}{A f_{y}}=\frac{A_{e f f} f_{y}}{A f_{y}}=\frac{A_{e f f}}{A} \approx \rho_{c}
$$

\subsection{EC9 framework}

The local buckling reduction factor is implemented in EC9 through an effective thickness formula. A first requirement of the formula is that it is compatible with the Class 3 slenderness limit (i.e. when the slenderness of an element is equal to the Class 3 limit, its local buckling factor $\rho_{\mathrm{c}}$ should be equal to unity). For aluminium alloy internal elements, it was proposed that the Class 3 limit for Class B material is harmonized with the limit for 
Class A material $(\beta / \varepsilon=22.0)$. For consistency, it is also proposed that the effective thickness formula for Class A material, specified in Clause 6.1.5 of EC9 (see Equation (7)), be adopted for Class B alloys. The normalised compression resistances $N_{u} / A f_{y}$ versus the slenderness parameter $\beta / \varepsilon$ are plotted in Figs 9(a) and 9(b), together with the curve from the effective thickness formula. It is demonstrated in Figs 9(a) and 9(b) that Class 4 sections of both Class A and B materials can be accurately represented by the same design curve, given by Equation (7).

For outstand elements, it is proposed herein that the existing Class 3 limit in EC9 $(\beta / \varepsilon=6.0)$ is retained for Class A material. Hence, the effective thickness formula (Equation (8)) currently given in Clause 6.1.5 of EC9 [2] is assessed against more than 200 compression test results. The curve (Equation (8)), which is shown Fig. 9(c), may be seen to provide a reasonable and safe fit to the test data. It is suggested to retain the current effective thickness formula for outstand elements of Class A aluminium alloys.

$$
\begin{aligned}
& \rho_{c}=\frac{32}{(\beta / \varepsilon)}-\frac{220}{(\beta / \varepsilon)^{2}} \text { for } \beta / \varepsilon>22.0 \\
& \rho_{c}=\frac{10}{(\beta / \varepsilon)}-\frac{24}{(\beta / \varepsilon)^{2}} \text { for } \beta / \varepsilon>6.0
\end{aligned}
$$

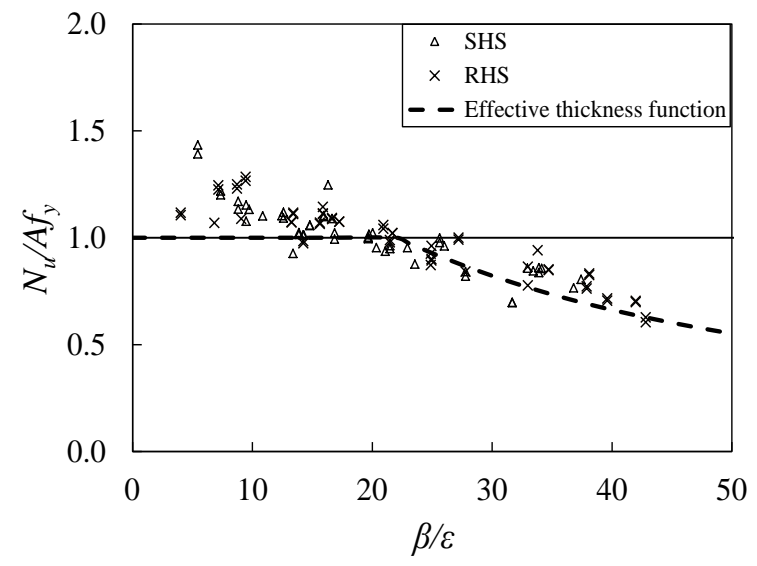

(a)

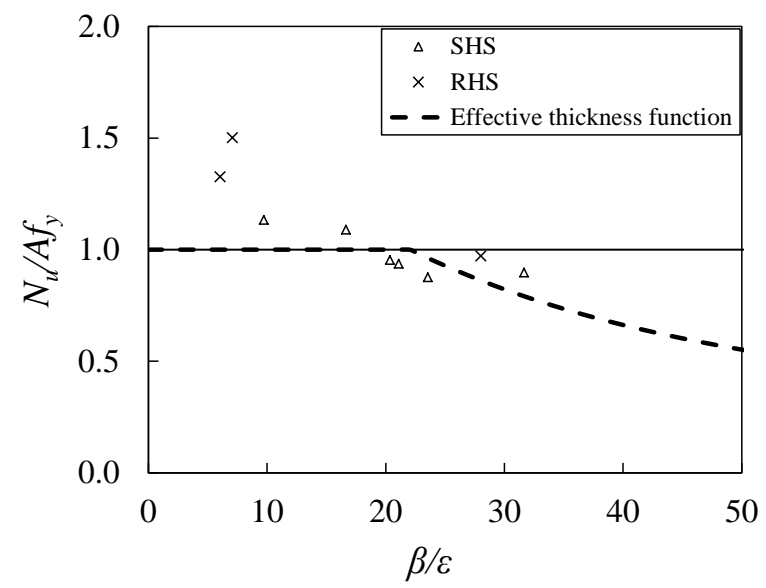

(b) 


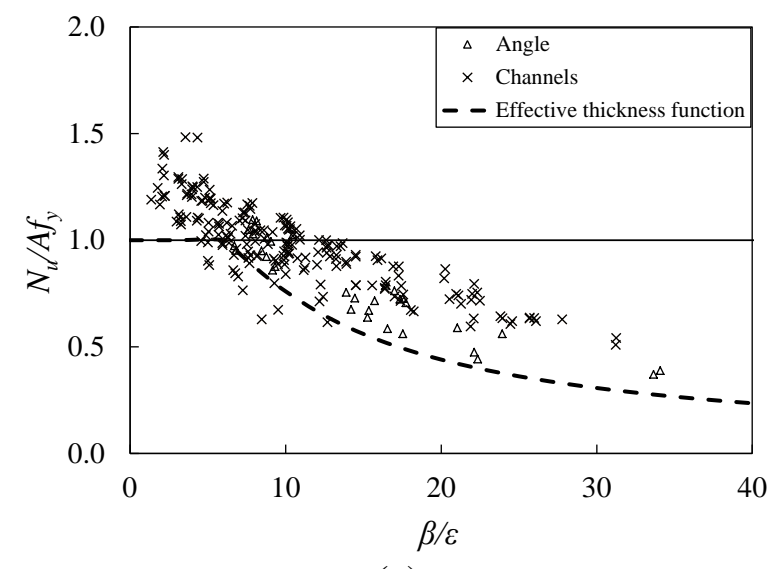

(c)

Fig. 9. Relationship between $N_{u} / A f_{y}$ and $\beta / \varepsilon$ for (a) internal elements of Class A material, (b) internal elements of Class B material and (c) outstand elements of Class A material

\subsection{Classification framework based on full cross-section slenderness}

In the classification framework based on full cross-section slenderness, the effective thickness formula is now presented in terms of the slenderness parameter $\bar{\lambda}_{p}$ for compatibility with the approach of Section 4 . The relationship between the normalised capacity $N_{u} / A f_{y}$ (i.e. the local buckling reduction factor $\rho_{\mathrm{c}}$ ) and slenderness $\bar{\lambda}_{p}$ can be expressed in the same general format as the DSM design curve [4], the CSM base curve for slender sections [38], as well as the Winter curve [39]. On this basis, Su et al. [38] proposed the expression given by Equation (9). A total of 346 available test results on compressed aluminium alloy crosssections is plotted in Fig. 10, including Class A and B materials, as well as internal and outstand elements. It can be observed that the proposed expression provides a good representation of the collected data.

$$
\rho_{c}=\frac{1}{\bar{\lambda}_{p}^{1.05}}-\frac{0.222}{\bar{\lambda}_{p}^{2.1}} \quad \text { for } \quad \bar{\lambda}_{p}>0.68
$$




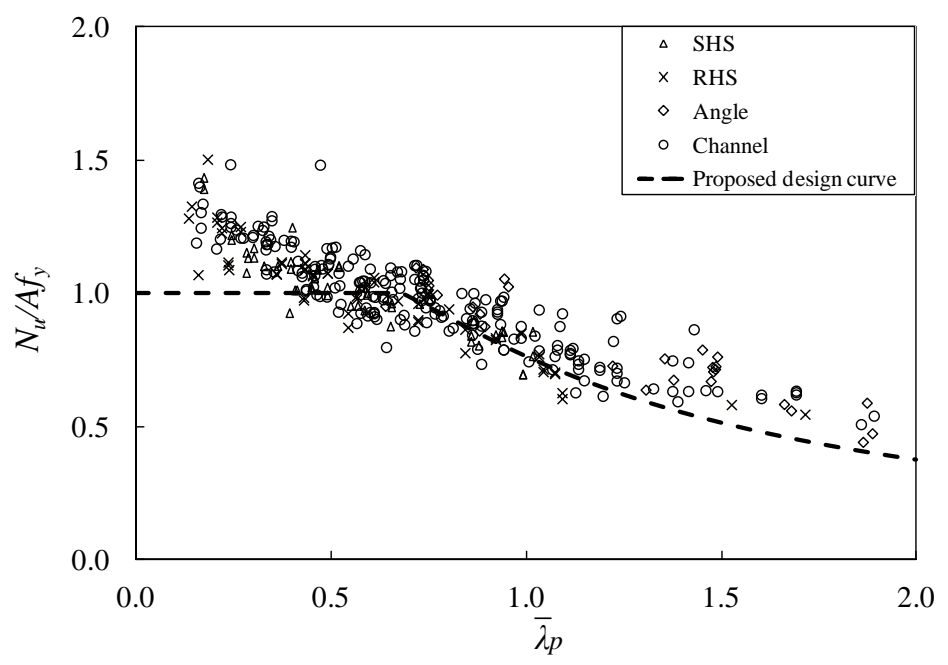

Fig. 10. Relationship between $N_{\mathrm{u}} / A f_{\mathrm{y}}\left(\rho_{c}\right)$ and $\bar{\lambda}_{p}$ for all cross-sections in compression

\section{Comparison of results and reliability analysis}

In order to verify the suitability of the proposed slenderness limits and the corresponding effective thickness formulae, reliability analysis was performed against a total of approximately 900 collected experimental and numerical results. The analysis was performed using the first order reliability method (FORM) and criteria set out in EN 1990 [40]. The random variables were the key geometric and material properties featuring in the EC9 cross-section resistance functions. The parameters adopted in the statistical analyses were taken from Annex D of the AA [25]: the mean values $\left(M_{\mathrm{m}}\right.$ and $\left.F_{\mathrm{m}}\right)$ and $\operatorname{COV}\left(V_{m}\right.$ and $V_{\mathrm{F}}$ ) for material properties and fabrication variables were taken as $M_{m}=1.10$ (over-strength for behaviour governed by the yield stress) and 1.00 (over-strength for behaviour governed by the ultimate stress), $F_{m}=1.00, V_{M}=0.06$ and $V_{F}=0.05$, while the assumed distributions were as set out in EN 1990 [40]. The target partial safety factor $\gamma_{M 0}$ is recommended to be 1.10 in EC9 [2]. 
The reliability analyses were performed for the Classes 2 and 3 slenderness limits using the following steps: first, a best fit line was fitted to the experimental and numerical data sets using least squares regression, as shown in Figs 11-14; second, the best fit line was scaled down to obtain the design resistance line $r_{\mathrm{d}}$; third, to allow for the effect of the material over-strength (i.e. $f_{\text {mean }} / f_{\text {nom }}$ ), the design resistance equations were multiplied by this ratio; finally, the required partial factor $\gamma_{\mathrm{M} 0}$ for the different slenderness limits was defined as the ratio of the nominal resistance, from the EC9 resistance model, to the design resistance $\left(r_{\mathrm{d}} \times f_{\mathrm{y}, \mathrm{mean}} / f_{\mathrm{y}, \text { nom }}\right)$.

\subsection{Stub columns}

The design approaches in EC9 [2] were used together with the existing and proposed slenderness limits, as well as the effective thickness formulae, to predict the capacities of 346 stub columns. The accuracy of the existing and proposed slenderness limits is shown in Table 3. According to Table 3, the predicted capacities were found to be more accurate when adopting the newly proposed slenderness limits. Meanwhile, the coefficients of variation (COV) are also reduced when using the proposed slenderness limits.

Table 3. Comparison between stub column results (346 data points) and Eurocode 9 design strengths with existing and proposed slenderness limits

\begin{tabular}{llccc}
\hline Stub columns & Existing & $\begin{array}{c}\text { New limits } \\
\text { in EC9 } \\
\text { framework }\end{array}$ & $\begin{array}{c}\text { New limits in } \\
\text { full cross- } \\
\text { section } \\
\text { slenderness } \\
\text { framework }\end{array}$ \\
\hline$N_{u} / N_{\text {EC9 }}$ & Mean & 1.18 & 1.12 & 1.08 \\
\hline$N_{u} / N_{\text {EC9-Annex F }}$ & COV & 0.168 & 0.113 & 0.113 \\
\hline
\end{tabular}


The stub column test data were also used to assess the partial factor $\gamma_{M 0}$, in accordance with the aforementioned procedure. For the EC9 slenderness limits, the test results for Class A and B material were used together to perform the reliability analysis, owing to the limited number of results for cross-sections of Class B material. The required value of $\gamma_{M 0}$ for the Class 3 slenderness limit for internal elements under uniform compression $(\beta / \varepsilon=22.0)$ was found to be 1.36, as shown in Fig. 11(a), which is higher than the target value of 1.10. However, the slenderness limit $\beta / \varepsilon=22.0$ has been utilised in EC9 for some years, and may therefore be considered, on the basis of historical precedent, to be satisfactory for aluminium alloy cross-sections in compression. For outstand elements such as angles and channels, the required value of $\gamma_{M 0}$ was found to be 1.24, as illustrated in Fig. 11(b). For classification based on the full cross-section slenderness, the required value of $\gamma_{M 0}$ for the Class 3 slenderness limit was found to be 1.33; again, although this is greater than 1.10 , the proposed Class 3 slenderness limit of $\bar{\lambda}_{p}=0.68$ does , in fact, correspond to the existing slenderness limit $\beta / \varepsilon=22.0$ in EC9, and is stricter than the equivalent slenderness limit employed in the DSM of $\bar{\lambda}_{p}=0.776$ for carbon steel [4] and $\bar{\lambda}_{p}=0.713$, which has been proposed for aluminium alloys [17]. On this basis, the proposed limit of 0.68 is deemed acceptable.

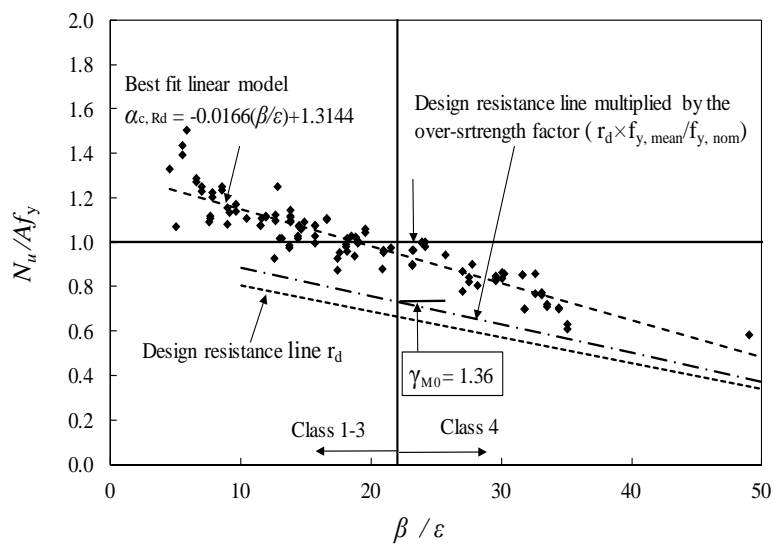

(a)

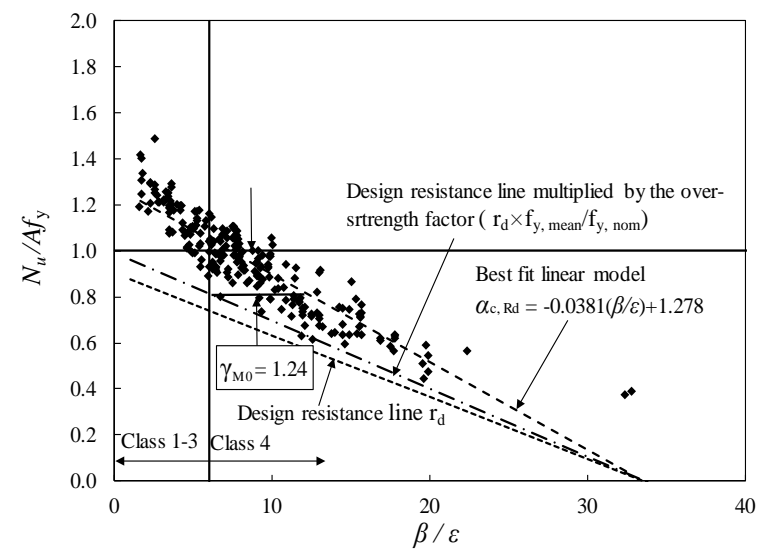

(b)

Fig. 11. Determination of $\gamma_{M 0}$ for uniformly compressed (a) internal elements and (b) outstand elements in the EC9 classification framework 


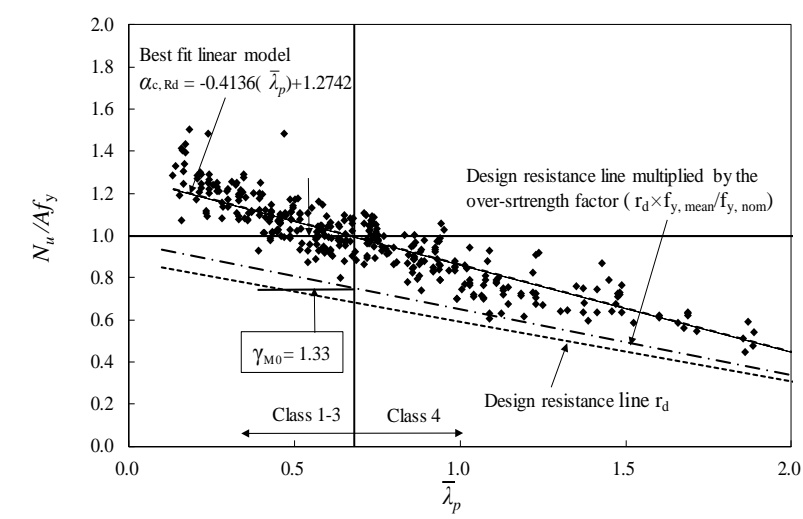

Fig. 12. Determination of $\gamma_{M 0}$ for uniformly compressed cross-sections in the classification framework based on full cross-section slenderness

\subsection{Simply supported beams}

In this section, the cross-section bending resistances obtained from the experiments and FE analyses are compared with the design strengths predicted by EC9 [2], as summarized in Table 4. On average, the proposed slenderness limits in both the EC9 and full cross-section slenderness frameworks yield slightly improved design accuracy, but with similar levels of scatter compared with the existing classification limits. The harmonised slenderness limits apply to both Class A and Class B aluminium alloys.

Table 4. Comparison between simply supported beam results (283 data points) and the Eurocode 9 design strengths based on existing and proposed slenderness limits

\begin{tabular}{llccc}
\hline $\begin{array}{l}\text { Simply supported } \\
\text { beams }\end{array}$ & Existing & $\begin{array}{c}\text { New limits } \\
\text { in EC9 } \\
\text { framework }\end{array}$ & $\begin{array}{c}\text { New limits in } \\
\text { full cross- } \\
\text { section } \\
\text { slenderness } \\
\text { framework }\end{array}$ \\
\hline$M_{u} / M_{\text {EC9 }}$ & Mean & 1.28 & 1.27 & 1.26 \\
\hline \multirow{2}{*}{$M_{u} / M_{\text {EC9-Annex F }}$} & COV & 0.152 & 0.158 & 0.161 \\
\hline
\end{tabular}

A statistical analysis was also carried out to assess the reliability of the slenderness limits for cross-sections in bending. Note that no statistical analysis has been conducted for 
the Class 1 limit due to the inherently highly scattered nature of rotation capacity data [1, 41 , 42]. In terms of the Class 2 and 3 slenderness limits in the EC9 framework, the key results are shown in Figs. 13 and 14 for Class A and B material, respectively. Following the EN 1990 reliability analysis, the required partial factors $\gamma_{M 0}$ were found to be 1.10 or less for all cases except the Class 2 limit for Class A material, where a value of 1.20 was determined. Meanwhile, for the classification framework based on the full cross-section slenderness (see Figs. 15 and 16), the evaluated partial factors $\gamma_{M 0}$ were found to be 1.23 (Class A material) and 1.11 (Class B material) for the Class 2 slenderness limit, and 1.17 (Class A material) and 1.19 (Class B material) for the Class 3 slenderness limit. The results of the statistical analysis suggest that the current partial factor of 1.10 is suitable for some but not all of the cases considered. However, given that the indicated required partial factors are not significantly higher than 1.10, and that the considered data come from a wide range of sources, which would be expected to result in increased scatter, the current value of $\gamma_{M 0}=1.10$ is deemed to be acceptable.

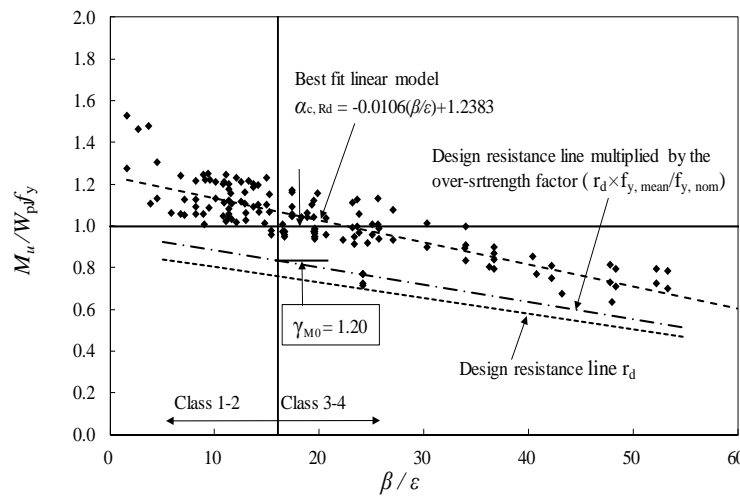

(a)

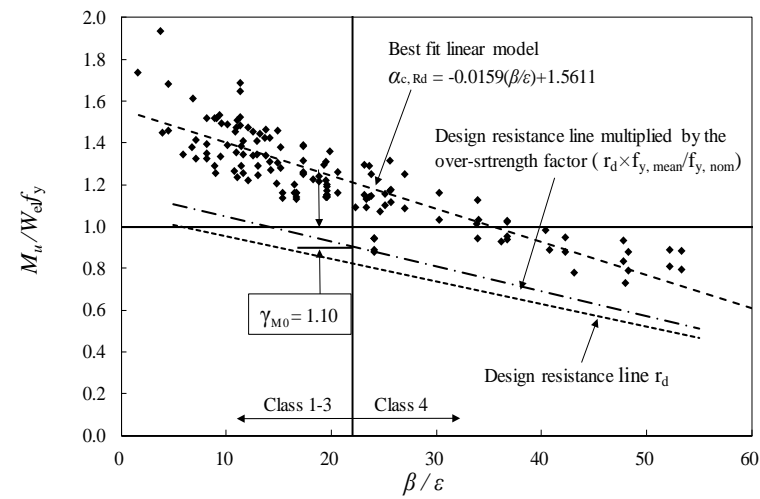

(b)

Fig. 13. Assessment of (a) Class 2 and (b) Class 3 slenderness limits in the EC9 classification framework for cross-sections of Class A material in bending 


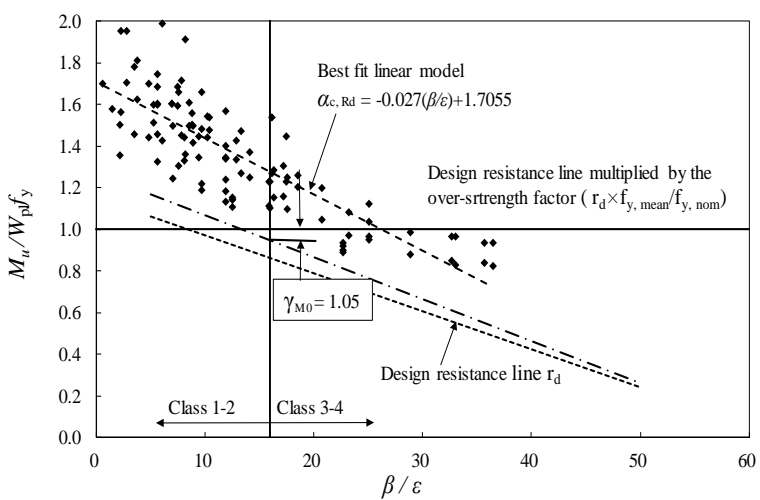

(a)

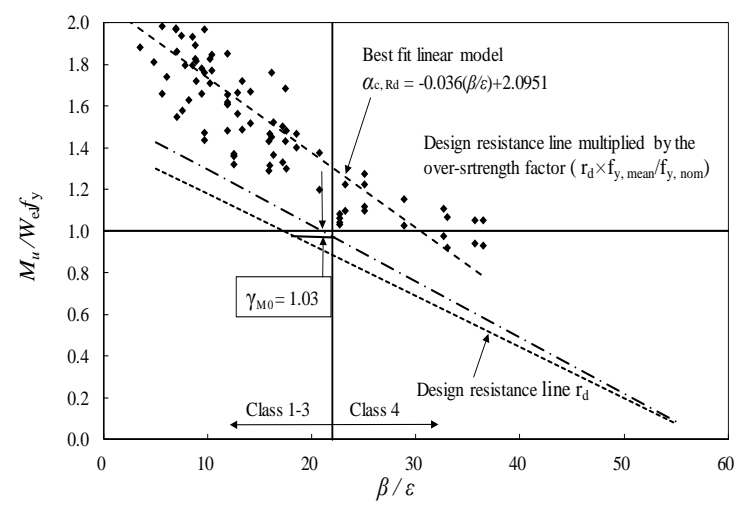

(b)

Fig. 14. Assessment of (a) Class 2 and (b) Class 3 slenderness limits in the EC9 classification framework for cross-sections of Class B material in bending

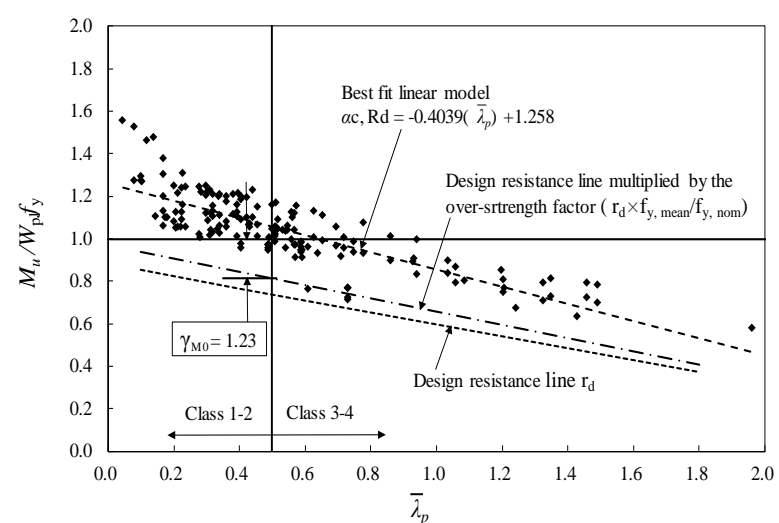

(a)

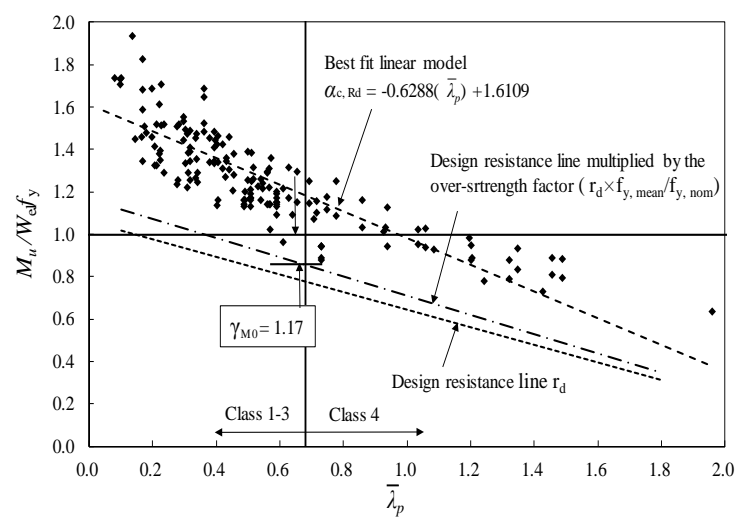

(b)

Fig. 15 Assessment of (a) Class 2 and (b) Class 3 slenderness limits in the classification framework based on full cross-section slenderness for cross-sections of Class A material in bending

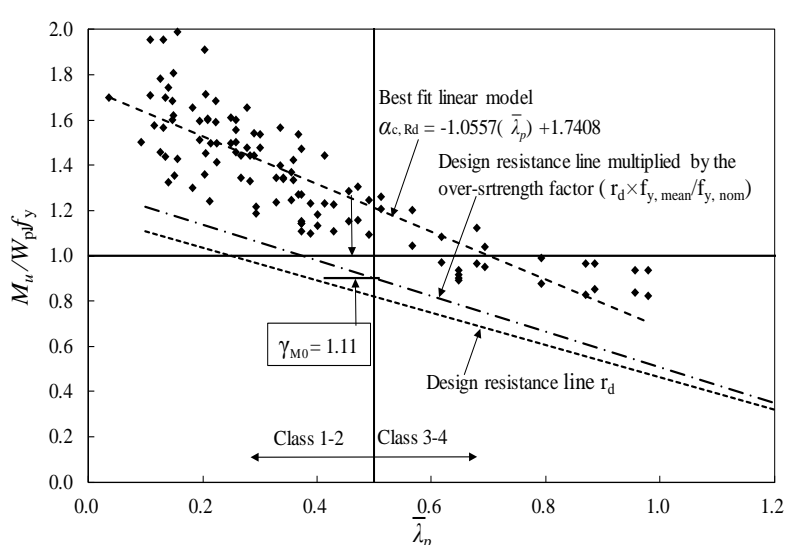

(a)

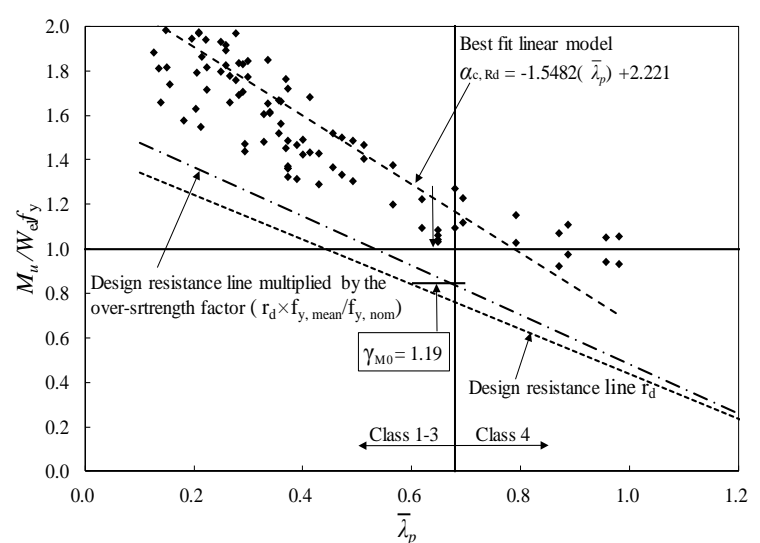

(b)

Fig. 16 Assessment of (a) Class 2 and (b) Class 3 slenderness limits in the classification framework based on full cross-section slenderness for cross-sections of Class B material in bending 


\subsection{Continuous beams}

The slenderness limits examined in the previous sections in relation to stub column and simply supported beam data, are assessed in this section with respect to test and numerical results on continuous beams. This allows the applicability of the existing and new slenderness limits for indeterminate structures to be assessed. Comparisons between the ultimate loads

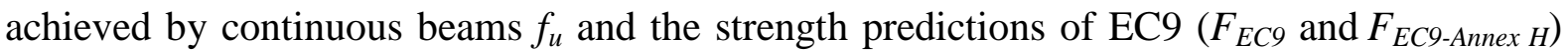
are shown in Table 5. The comparisons reveal slightly improved average strength predictions when the new slenderness limits are adopted, but remaining on the safe side, as well as a general reduction in scatter.

Table 5. Comparison between continuous beam results (256 data points) and EC9 design strengths based on existing limits and proposed limits

\begin{tabular}{|c|c|c|c|c|}
\hline \multicolumn{2}{|c|}{ Continuous beams } & $\begin{array}{c}\text { Existing } \\
\text { limits }\end{array}$ & $\begin{array}{l}\text { New limits } \\
\text { in EC9 } \\
\text { framework }\end{array}$ & $\begin{array}{l}\text { New limits in } \\
\text { full cross- } \\
\text { section } \\
\text { slenderness } \\
\text { framework }\end{array}$ \\
\hline \multirow{2}{*}{$F_{u} / F_{E C 9}$} & Mean & 1.63 & 1.63 & 1.62 \\
\hline & $\mathrm{COV}$ & 0.223 & 0.222 & 0.222 \\
\hline \multirow{2}{*}{$F_{u} / F_{\text {EC9- Annex } H}$} & Mean & 1.40 & 1.38 & 1.33 \\
\hline & $\mathrm{COV}$ & 0.193 & 0.204 & 0.185 \\
\hline
\end{tabular}

\section{Conclusions}

Eurocode 9 (EC9) is widely used for the design of aluminium alloy structural elements and provides slenderness limits for the classification of cross-sections to account for local buckling. In this paper, all relevant experimental and numerical results on aluminium alloy cross-sections have been gathered, covering square and rectangular hollow sections of Class A and B material, as well as I sections, angles and channels of Class A material. The collected data were used to carry out a comprehensive assessment of the existing slenderness 
limits for all 4 cross-section classes in EC9 and to assess the feasibility of harmonising the slenderness limits for Class A and B aluminium alloys. Revised slenderness limits are recommended based on the findings. In addition, a classification framework based on the full cross-section slenderness, as adopted in the DSM and CSM, is proposed, with corresponding slenderness limits and an effective thickness formula for Class 4 cross-sections. Finally, reliability analyses have been performed to verify the suitability of the proposed slenderness limits in both classification frameworks according to EN 1990 based on the collected experimental and numerical results on aluminium alloy stub columns and beams.

\section{Acknowledgement}

The research work described in this paper was supported by a grant from The University of Hong Kong under the seed funding program for basic research.

\section{Notation}

$\begin{array}{ll}A & =\text { Cross-sectional area } \\ A_{\text {eff }} & =\text { Effective cross-sectional area } \\ b & =\text { Flat width of flange } \\ E & =\text { Young's modulus } \\ f_{c s m} & =\text { CSM limiting stress } \\ f_{y} & =\text { Yield strength, taken as the } 0.2 \% \text { proof stress } \\ f_{y, \text { mean }} & =\text { Measured yield strength from tensile coupon tests } \\ f_{y, \text { nom }} & =\text { Nominal yield strength } \\ F_{E C 9} & =\text { Ultimate load predicted by EC9 }\end{array}$




$$
\begin{aligned}
& F_{E C 9-A n n e x H} \quad=\text { Ultimate load predicted by the plastic hinge method in Annex H of EC9 } \\
& F_{u} \quad=\text { Experimental or numerical ultimate load of continuous beams } \\
& F_{m} \quad=\text { Mean value of fabrication factor } \\
& h \quad=\text { Flat depth of web } \\
& M_{E C 9} \quad=\text { Ultimate moment capacity predicted by EC9 } \\
& M_{E C 9-A n n e x F}=\text { Ultimate moment capacity predicted by Annex F of EC9 } \\
& M_{e l} \quad=W_{e l} f_{y} \text { is the elastic moment capacity } \\
& M_{u} \quad=\text { Experimental or numerical ultimate moment of simply supported beams } \\
& M_{m} \quad=\text { Material over-strength } \\
& M_{p l} \quad=W_{p l} f_{y} \text { is the plastic moment capacity } \\
& N_{E C 9} \quad=\text { Ultimate load of stub columns predicted by EC9 [2] } \\
& N_{E C 9-A n n e x ~ F} \quad=\text { Ultimate load of stub columns predicted by Annex F of EC9 [2] } \\
& N_{u} \quad=\text { Experimental or numerical ultimate load of stub columns } \\
& t \quad=\text { Thickness } \\
& t_{\text {eff }} \quad=\text { Effective thickness } \\
& R \quad \quad=\text { Rotation capacity } \\
& V_{F} \quad=\text { Coefficient of variation of fabrication factor } \\
& V_{M} \quad=\text { Coefficient of variation of material factor } \\
& W_{e l} \quad=\text { Elastic section modulus } \\
& W_{p l} \quad=\text { Plastic section modulus } \\
& \beta / \varepsilon \quad=\text { Slenderness parameter employed in EC9 } \\
& \gamma_{M O}=\text { Required partial safety factor at slenderness limit under consideration } \\
& \bar{\lambda}_{p} \quad=\text { Cross-section } / \text { plate slenderness } \\
& \rho_{c} \quad=\text { Local buckling reduction factor } \\
& \kappa_{p l}=\text { Elastic curvature corresponding to the plastic moment } M_{p l}
\end{aligned}
$$




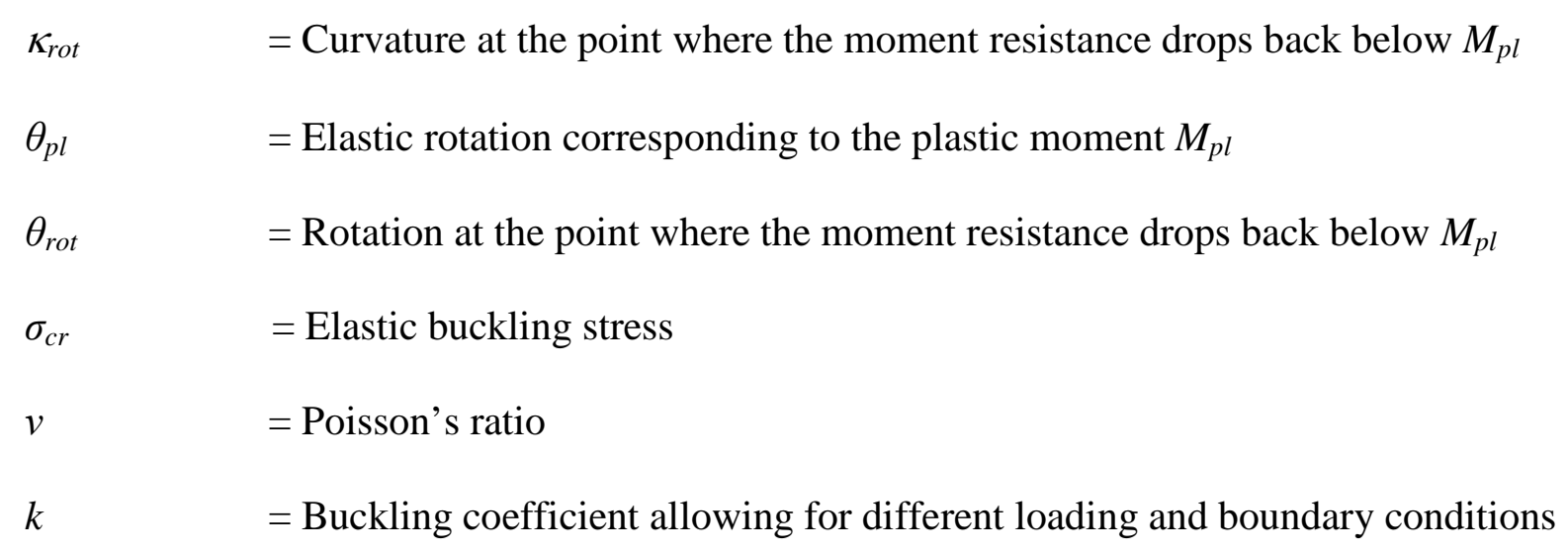

\section{References}

[1] Gardner, L. and Theofanous, M. (2008). “Discrete and continuous treatment of local buckling in stainless steel elements.” Journal of Constructional Steel Research 64(11): 1207-1216.

[2] European Committee for Standardization (EC9). (2007). "Eurocode 9: Design of aluminum structures-Part 1-1: General rules-General rules and rules for buildings.” BS EN 1999-1-1:2007, CEN.

[3] Su, M., Young, B. and Gardner, L. (2014) “Testing and design of aluminum alloy cross-sections in compression.” Journal of Structural Engineering, ASCE, 140(9), 04014047.

[4] Schafer, B.W. and Peköz, T. (1998). "Direct strength prediction of cold-formed steel members using numerical elastic buckling solutions.” Proceeding of 14th Int. specialty conference on cold-formed steel structures, pp. 69 - 76. University of Missouri-Rolla, Rolla, Mo

[5] Marmo F. and Rosati, L. (2015), “Automatic cross-section classification and collapse load evaluation for steel/aluminum thin-walled sections of arbitrary shape”, Engineering Structures, 100, 57-65. 
[6] Langseth, M. and Hopperstad, O. S. (1997). "Local buckling of square thin-walled aluminum extrusions” Thin-Walled Structures 27(1):117-126.

[7] Mazzolani, F.M., Faella, C., Piluso, V. and Rizzano, G. (1996), “Experimental analysis of aluminum alloy SHS-members subjected to local buckling under uniform compression.” Proceeding of 5th International Colloquium on Structural Stability, pp. 475-488, SSRC, Rio de Janeiro, Brazil (Apr, 1996).

[8] Mazzolani, F. M., Faella, C., Piluso, V. and Rizzano, G. (1997). "Local buckling of aluminum alloy RHS-members: experimental analysis.” Proceeding of XVI Congresso C.T.A., Italian Conference on Steel Construction, pp. 1-12, Collegio dei Tecnici dell’Acciaio, Ancona (Oct, 1997).

[9] Mazzolani, F.M., Faella, C., Piluso, V. and Rizzano, G. (1998). "Local buckling of aluminum members: experimental analysis and cross-sectional classification.” Department of Civil Engineering, University of Salerno, Italy

[10] Landolfo, R., Piluso, V., Langseth, M. and Hopperstad, O.S. (1999). "EC9 provisions for flat internal elements: comparison with experimental results.” LightWeight Steel and Aluminum Structures, pp. 515-522.

[11] Hassinen, P. (2000). “Compression strength of aluminium columns - Experimental and numerical studies.” Proceedings of the 3rd International Conference on Coupled Instabilities of Metal Structures, pp.241-248, CIMS’2000, ICP, London, UK

[12] Mennink, J. (2002). Cross-Sectional Stability of Aluminium Extrusions: Prediction of the Actual Local Buckling Behaviour. The Netherlands.

[13] Zhu, J.H., and Young, B. (2006). “Tests and design of aluminum alloy compression members.” Journal of Structural Engineering, ASCE 132(7):1096-1107.

[14] Zhu, J.H. and Young, B. (2008). "Behavior and design of aluminum alloy structural members.” Advanced Steel Construction 4(2):158-172. 
[15] Mazzolani, F. M., Piluso, V. and Rizzano, G. (2001), "Experimental analysis of aluminum alloy channels subjected to local buckling under uniform compression.” Proceeding of C.T.A., Italian Conference on Steel Construction ACS, 1-10, Acai Servizi, Milano, Italy (Sep, 2001).

[16] Mazzolani, F.M., Piluso, V., and Rizzano, G. (2011), "Local buckling of aluminum alloy angles under uniform compression.” Journal of Structural Engineering, ASCE 137(2):173-184.

[17] Zhu, J.H. and Young, B. (2009). “Design of aluminum alloy flexural members using direct strength method.” Journal of Structural Engineering, ASCE, 135(5): 558-566.

[18] Su, M., Young, B. and Gardner, L. (2013), “Deformation-based design of aluminium alloy beams” Engineering Structures, 80:339-349.

[19] Su, M., Young, B. and Gardner, L., "Flexural resistance of aluminium alloy SHS and RHS with internal stiffeners”, Engineering Structures, 121: 170-180.

[20] Moen, L.A., Hopperstad, O.S. and Langseth M. (1999). "Rotational capacity of aluminum beams under moment gradient. I: experiments.” Journal of Structural Engineering, ASCE 125(8): 910-920.

[21] Lai, Y.F.W. and Nethercot, D.A. (1992). "Strength of aluminium members containing local transverse welds” Engineering Structures 14(4): 241-254.

[22] Zhu, J.H. and Young, B. (2006). “Experimental investigation of aluminum alloy thin-walled tubular members in combined compression and bending.” Journal of Structural Engineering, ASCE 132(12):1955-1966.

[23] Su, M., Young, B. and Gardner, L. (2015), “Continuous beams of aluminum alloy tubular cross-section - part I: tests and model validation”, Journal of Structural Engineering, ASCE, 141(9): 04014232. 
[24] Su, M., Young, B. and Gardner, L. (2015), “Continuous beams of aluminum alloy tubular cross-section - part II: parametric study and design”, Journal of Structural Engineering, ASCE, 141(9):04014233.

[25] Aluminum Association (AA). (2010). Aluminum design manual. Washington, D.C.

[26] Australian/New Zealand Standard (AS/NZS). (1997). “Aluminum structures part 1: Limit state design.” AS/NZS 1664.1:1997, Standards Australia, Sydney, Australia.

[27] Law and Gardner (2009). "Unified slenderness limits for circular hollow sections.” Proceeding of $6^{\text {th }}$ International Conference on Advances in Steel Structures, pp 293300, Hong Kong, China

[28] European Committee for Standardization (EC3). (2006) "Eurocode 3: Design of steel structures-Part 1-1: General rules - Supplementary rules for cold-formed members and sheeting”. EN 1993-1-1:2006, CEN.

[29] European Committee for Standardization (EC3). (2006) "Eurocode 3: Design of steel structures-Part 1-4: General rules - Supplementary rules for stainless steels”. EN 1993-1-4:2006, CEN.

[30] Chan, T.M. and Gardner, L. (2008). "Bending strength of hot-rolled elliptical hollow sections” Journal of Construction Steel Research 64(9): 971-986

[31] Gardner, L., Saari, N. and Wang F. (2010) “Comparative experimental study of hotrolled and cold-formed rectangular hollow sections” Thin-Walled Structures, 48 (7): $495-507$.

[32] Theofanous, M., Chan, T.M. and Gardner, L. (2009). "Flexural behaviour of stainless steel oval hollow sections.” Thin-walled Structures 47(6-7), 776-787.

[33] Theofanous, M., Saliba, N., Zhao, O. and Gardner, L. (2014) “Ultimate response of stainless steel continuous beams.” Thin-Walled Structures, 83, 115-127. 
[34] Faella, C., Mazzolani, F. M., Piluso, V. and Rizzano, G. (2000) "Local buckling of aluminum members: testing and classification” Journal of Structural Engineering, ASCE, 126(3): 353-360.

[35] Zhou, F., Chen, Y and Young, B. (2013) “Cold-formed high strength stainless steel cross-sections in compression considering interaction effects of constituent plate elements” Journal of Constructional Steel Research, 80: 32-41

[36] Seif, M. and Schafer, B.W. (2010). "Local buckling of structural steel shapes.” Journal of Constructional Steel Research 66(10): 1232-1247.

[37] Li, Z. and Schafer, B.W. (2010) "Buckling analysis of cold-formed steel members with general boundary conditions using CUFSM: conventional and constrained finite strip methods.” Proceedings of the 20th International Special Conference on Cold-Formed Steel Structures, pp.17-31, St. Louis, MO.

[38] Su, M., Young, B. and Gardner, L.(2016), “The continuous strength method for the design of aluminium alloy structural elements” Engineering Structures, 122:338-348.

[39] Winter, G. (1940) Stress distribution in and equivalent width of flanges of wide, thin walled steel beams, Technical Note 784, National Advisory Committee for Aeronautics.

[40] European Committee for Standardization (EN 1990) (2002). "Eurocode: Basis of Structural Design.” EN 1990-2002, CEN.

[41] Wang, J., Afshan, S., Gkantou, M., Theofanous, M., Baniotopoulos, C. and Gardner, L., (2016), "Flexural behaviour of hot-finished high strength steel square and rectangular hollow sections”, Journal of Constructional Steel Research, 121: 97-109.

[42] Gardner, L. and Nethercot, D.A. (2004), "Numerical modeling of stainless steel structural components - a consistent approach”, Journal of Structural Engineering, ASCE, 130 (10): 1586 - 1601. 